\title{
Article \\ Interleukin-1 $\alpha$ Is a Critical Mediator of the Response of Human Bronchial Fibroblasts to Eosinophilic Inflammation
}

\author{
Ksenija Bernau *, Jonathan P. Leet, Heather Floerke, Ellen M. Bruhn, Andrea L. Noll, Ivy S. McDermott, \\ Stephane Esnault, Nizar N. Jarjour and Nathan Sandbo
}

check for

updates

Citation: Bernau, K.; Leet, J.P.;

Floerke, H.; Bruhn, E.M.; Noll, A.L.;

McDermott, I.S.; Esnault, S.; Jarjour,

N.N.; Sandbo, N. Interleukin- $1 \alpha$ Is a Critical Mediator of the Response of Human Bronchial Fibroblasts to Eosinophilic Inflammation. Cells 2021, 10, 528. https://doi.org/10.3390/ cells10030528

Academic Editor: Rudi Hendriks

Received: 11 February 2021

Accepted: 23 February 2021

Published: 2 March 2021

Publisher's Note: MDPI stays neutral with regard to jurisdictional claims in published maps and institutional affiliations.

Copyright: (c) 2021 by the authors. Licensee MDPI, Basel, Switzerland. This article is an open access article distributed under the terms and conditions of the Creative Commons Attribution (CC BY) license (https:/ / creativecommons.org/licenses/by/ $4.0 /)$.
Department of Medicine, Division of Allergy, Pulmonary and Critical Care Medicine, School of Medicine and Public Health, University of Wisconsin-Madison, Madison, WI 53792, USA; jleet@wisc.edu (J.P.L.); hlfloerke@medicine.wisc.edu (H.F.); ebruhn@dermatology.wisc.edu (E.M.B.); alnoll@wisc.edu (A.L.N.); imcdermott@wisc.edu (I.S.M.); sesnault@medicine.wisc.edu (S.E.); nnj@medicine.wisc.edu (N.N.J.); nsandbo@medicine.wisc.edu (N.S.)

* Correspondence: kbernau@medicine.wisc.edu; Tel.: +1-60-(82)-623518

Abstract: Eosinophils contribute to allergic inflammation in asthma in part via elaboration of a complex milieu of soluble mediators. Human bronchial fibroblasts (HBF) respond to stimulation by these mediators by acquiring a pro-inflammatory profile including induction of interleukin 6 (IL6) and IL8. This study sought to determine key component(s) of eosinophil soluble factors that mediate IL6 and IL8 induction in HBF. HBF treated with eosinophil-derived soluble mediators were analyzed for gene expression, intracellular signaling, and IL6 and IL8 secretion following inhibition of inflammatory signaling. Segmental allergen bronchoprovocation (SBP-Ag) was performed in mild asthmatics and bronchoalveolar lavage fluid was analyzed for eosinophils and cytokines. We found that signaling via the IL1 $\alpha /$ IL1 receptor is an essential component of the response of HBF to eosinophil-derived soluble factors. IL1 $\alpha$-dependent activation of nuclear factor kappa-light-chainenhancer of activated B cells (NFkB) signaling is required to induce IL6 secretion. However, NFkB signaling is dispensable for the induction of IL8, whereas Src is required. IL1 $\alpha$ is associated with eosinophilic inflammation in human airways after SBP-Ag. Conclusions: IL1 $\alpha$ appears to be a critical component of the soluble eosinophil-derived milieu that drives pro-inflammatory bronchial fibroblast responses and associates with eosinophilic inflammation following SBP-Ag. Disruption of IL1 $\alpha-$ signaling could modify the downstream effects of eosinophilic inflammation on airway remodeling.

Keywords: eosinophil; fibroblast; asthma; IL6; IL8; IL1 $\alpha$; IL1 receptor; cytokines; intracellular signaling

\section{Introduction}

Eosinophilic inflammation is a hallmark of allergic asthma. Eosinophil presence in the asthmatic airway is associated with increased disease severity and risk of exacerbations [1,2]. Airway eosinophils contribute to allergic inflammation in asthma by releasing a variety of soluble mediators and cell-free granule proteins through cytolysis and degranulation [3-5]. These factors contribute to the pro-inflammatory activation of other cell types, including bronchial fibroblasts, resulting in prolonged tissue injury that can lead to airway remodeling and subsequent irreversible airflow obstruction in some subjects [6-8]. The presence of irreversible airflow obstruction poses a major treatment dilemma in some severe asthmatics, given the paucity of effective therapeutics that target airway remodeling.

Eosinophilic inflammation plays an essential role in airway remodeling [9], and while the role of the bronchial fibroblast in asthma tissue remodeling is equally evident $[10,11]$, a detailed understanding of the interplay between airway eosinophilia and bronchial fibroblast activation is lacking, holding back the development of targeted therapeutics to address this problem. In asthmatic airways, activated eosinophils release a myriad of soluble and insoluble components (see Review [12]), including granules containing major basic protein, eosinophil cationic protein (ECP), and eosinophil-derived neurotoxin 
(EDN), which can cause direct damage to airway epithelium [13]. Eosinophils have been observed to release cytokines important in fibroblast activation and function, including transforming growth factor $\beta$ (TGF- $\beta$ ) [14], and co-culture of eosinophils with fibroblasts promotes the production of extracellular matrix (ECM) components [15,16]. However, previous studies have typically utilized approaches where identified eosinophil-derived mediators are tested in isolation to observe effects on secondary structural cell cultures. While these studies have led to a critical mechanistic understanding of potential signaling that may result from these mediators, it is unclear how the milieu of the released products by eosinophils affects bronchial fibroblasts in aggregate.

In our previous work, we sought to begin to answer this question by utilizing an ex vivo model of human primary eosinophil cultures that both recapitulates the phenotype of asthmatic airway eosinophils and also enables inducible cytolysis and degranulation on heat-aggregated immunoglobulin $\mathrm{G}(\mathrm{IgG})$, mimicking eosinophil interactions with immunoglobulins found in vivo [5,6,17]. Using this model, we isolated the supernatants from cytolyzing and degranulating eosinophils, and, using a global transcriptomic approach, found that exposure of human lung fibroblasts to the complete milieu of eosinophil-derived soluble mediators results in the development of a pro-inflammatory gene expression profile $[7,17]$. We additionally found that stimulation of human bronchial fibroblasts (HBF) with eosinophil-derived soluble mediators results in the elaboration of two key inflammatory factors, interleukin 8 (IL8) and interleukin 6 (IL6) [6]. However, the dominant component(s) released from the degranulating/cytolyzing eosinophils that drive these airway fibroblast responses is not known. Because identification of these components would lend important insight into how bronchial fibroblasts respond in aggregate to eosinophilic inflammation and provide a potential target for intervention, in this study, we sought to characterize the primary activator and signals driving bronchial fibroblast responses to eosinophil-derived soluble mediators. Using our previous transcriptomic data and pathway analysis as a guide [7], we hypothesized that eosinophil soluble mediators signal to HBF through the IL1 receptor (IL1R) leading to the pro-inflammatory fibroblast phenotype. In this study, we have found that upon stimulation with eosinophil soluble mediators, HBF are activated through IL1R by IL1 $\alpha$, but not IL1 $\beta$, leading to the activation of divergent intracellular signaling pathways that lead to the release of IL6 and IL8.

\section{Materials and Methods}

\subsection{Human Subjects and Cell Preparation}

This study was conducted according to the guidelines of the Declaration of Helsinki and approved by the University of Wisconsin-Madison Health Sciences Institutional Review Board (IRB\#2013-1570, IRB\#1999-292). All subjects provided written consent prior to participation.

Circulating blood eosinophils were obtained from donors with known allergy, rhinitis and/or asthma who underwent phlebotomy. Eosinophils were purified by negative selection as previously described [17]. Briefly, heparinized blood was diluted in Hank's balanced solution (HBSS, 1:1), overlaid above Percoll $(1.090 \mathrm{~g} / \mathrm{mL})$, centrifuged at $700 \times g$ for $20 \mathrm{~min}$ at room temperature (RT). Mononuclear cells were subsequently removed from the interface between Percoll and plasma, while red blood cells were lysed from the pellet. The remaining pellet containing polymorphonuclear leukocytes was suspended in $2 \%$ calf serum in HBSS and then incubated with anti-CD16, anti-CD3, anti-CD14, and anti-glycophorinA immunogenic beads (Mylteni, Bergisch Gladbach, Germany), leaving behind eosinophils with a purity and survival of $>99 \%$.

HBF were obtained from healthy non-atopic, non-smoking adult donors using bronchoscopy-driven bronchial biopsy specimens that were then de-identified. Bronchoscopy specimens were histologically assessed to confirm normal bronchial tissue architecture, and HBF were derived as before [18]. Briefly, tissue pieces were digested in fibroblast starvation medium (FGM) Bulletkit medium (CC-33132 Lonza, Basel, Switzerland) with collagenase $\mathrm{H}(1 \mathrm{mg} / \mathrm{mL})$ at $4{ }^{\circ} \mathrm{C}$ before being cultured in fibroblast growth 
medium, which included: FGM Bulletkit medium, 2\% fetal bovine serum (FBS), human recombinant insulin (CC-4021J, Lonza), recombinant human fibroblast growth factor-B (CC-4065J, Lonza) and gentamycin sulfate amphotericin B (GA1000, CC4081J, Lonza). A homogenous fibroblast population was established by expanding fibroblasts every several days.

We recruited 18 subjects who had a history of mild asthma with airway reversibility to albuterol and a positive skin prick test to one or more aeroallergens, to undergo in vivo segmental bronchoprovocation with antigen (SBP-Ag). The subjects were nonsmokers and did not have a respiratory infection or asthma exacerbation within 30 days of study, and had not received long-acting $\beta$-agonists within two days, antihistamines or leukotriene antagonists within seven days, or corticosteroids within 30 days of study enrollment. Bronchoscopy, bronchoalveolar lavage (BAL) and SBP-Ag were performed as previously described $[19,20]$. Briefly, the antigen dose leading to $20 \%$ forced expiratory volume in $1 \mathrm{sec}$ $\left(\mathrm{FEV}_{1}\right)$ fall $\left(\mathrm{Ag} \mathrm{PD}_{20}\right)$ was calculated from a dose-response curve generated by a graded inhaled antigen challenge. A total dose of $30 \%$ of the antigen $\mathrm{PD}_{20}$ was administered for SBP-Ag; $10 \%$ in one segment and $20 \%$ in a second segment. In all subjects, BAL was performed in each segment before and $48 \mathrm{~h}$ after SBP-Ag. BAL fluid from the two segments was pooled for fluid and cell analysis. Cell differentials were determined after cytospin and staining with Wright-Giemsa-based Hema-3 while BAL fluids were examined via ELISA (described below).

\subsection{Cell Cultures}

Eosinophils were cultured at $1 \times 10^{6}$ cells $/ \mathrm{mL}$ in medium containing RPMI 1640 with L-glutamine and 25 mM HEPES (Corning, Corning, NY, USA), 10\% FBS (Gibco, Thermo Fisher Scientific, Verona, WI, USA) with antibiotic/antimyotic (Gibco), 2 mM L-glutamine (Gibco) and $100 \mathrm{mg} / \mathrm{mL}$ ciprofloxacin-HCL, and IL3 (4 ng/mL, R\&D Systems Inc., Minneapolis, MN, USA) for $20 \mathrm{~h}$. Concurrently, heat aggregated human $\operatorname{IgG}(\operatorname{IgG})$ was prepared for $30 \mathrm{~min}$ at $63{ }^{\circ} \mathrm{C}$ in phosphate-buffered saline (PBS), as previously described [17]. After $20 \mathrm{~h}$ of incubation with IL3, eosinophils were washed and suspended at $1 \times 10^{6}$ cells $/ \mathrm{mL}$ in new medium without IL3, and $1 \times 10^{6}$ cells were moved to a 24 -well plate that had been previously coated overnight with IgG $(10 \mu \mathrm{g} / \mathrm{mL} ; 500 \mu \mathrm{L} /$ well, I-2511 Sigma Aldrich, St. Louis, MO, USA) and saturated with $0.1 \%$ gelatin for $30 \mathrm{~min}$ at $37^{\circ} \mathrm{C}$ in PBS. After $6 \mathrm{~h}$ of incubation on IgG, eosinophil supernatant fluids were collected and stored at $-80{ }^{\circ} \mathrm{C}$ for subsequent use for activation of $\mathrm{HBF}$.

$\mathrm{HBF}$ were maintained on tissue culture plastic and utilized for experiments between Passages 2 and 7. For experiments, HBF were plated at a density of 150,000 cells $/ \mathrm{mL}$ in fibroblast growth medium for $24 \mathrm{~h}$ prior to serum starving in fibroblast starvation medium (FGM Bulletkit medium with gentamycin sulfate amphotericin B and $0.4 \%$ FBS) for $24 \mathrm{~h}$. HBF inhibitors, including IL1 receptor antagonist (IL1RA, $100 \mathrm{ng} / \mathrm{mL}$, R\&D Systems, Inc.), inhibitor of Src-family kinases (PP2 and control (PP3), $10 \mu \mathrm{M}$, Cayman Chemical, Ann Arbor, MI, USA), IкB kinase inhibitor (BMS-345541, $10 \mu \mathrm{M}$, Cayman Chemical), and Janusassociated kinase (JAK) inhibitor (Ruxolitinib, $100 \mathrm{nM}$, Cayman Chemical), were added to HBF medium for 30 min prior to stimulation with eosinophil supernatant fluids or control medium (1:1 ratio with fibroblast starvation medium). Conversely, neutralizing antibodies, including anti-IL1 $\alpha(1 \mu \mathrm{g} / \mathrm{mL}$, mabg-hil1a-3, InvivoGen, San Diego, CA, USA) and antiIL1 $\beta(1 \mu \mathrm{g} / \mathrm{mL}$, mabg-hillb-3, InvivoGen), as well as IgG1 isotype control $(1 \mu \mathrm{g} / \mathrm{mL}$, mabg1-ctrlm, InvivoGen), were incubated with eosinophil supernatant fluids for $1 \mathrm{~h}$ at $37{ }^{\circ} \mathrm{C}$ prior to being added to HBF. HBF were treated with recombinant human IL $1 \alpha$ (1 ng/mL, 200-LA, R\&D systems) or IL1 $\beta$ ( $1 \mathrm{ng} / \mathrm{mL}, 201-\mathrm{LB}, \mathrm{R} \& D$ systems) agonists or eosinophil supernatants with or without inhibitors for $30 \mathrm{~min}$ or $24 \mathrm{~h}$, at which point $\mathrm{HBF}$ supernatants were collected ( $24 \mathrm{~h}$ incubation) while the cells were lysed for RNA ( $24 \mathrm{~h}$ incubation) or protein (30 min incubation) isolation. 


\subsection{ELISA}

Detection of IL6 and IL8 was performed by enzyme-linked immunosorbent assay (ELISA), as previously described [21], using the sandwich method. ELISA plate coating was done using mouse monoclonal anti-human IL8 (clone G265-5, BD Biosciences, San Jose, CA, USA) and IL6 (clone 6708 R\&D Systems, Inc.). For detection, biotinylated mouse monoclonal anti-human IL8 (clone G265-8, BD Biosciences) and biotinylated polyclonal goat anti-human IL6 (R\&D Systems, Inc.) were utilized with sensitivities of less than $3 \mathrm{pg} / \mathrm{mL}$ for IL8 and IL6.

BAL fluids were retrieved before and $48 \mathrm{~h}$ after SBP-Ag, concentrated 20-fold and IL1 $\alpha$ and IL1 $\beta$ concentrations were determined using a DuoSet Development kit (DY-200 and DY-201, respectively, R\&D Systems, Inc.), while EDN concentrations were determined using the sandwich ELISA kit (7630, MBL International Corp., Des Plaines, IL, USA). The IL1 $\alpha$ and IL1 $\beta$ DuoSet Development ELISA kits and EDN ELISA kit had sensitivities of $1 \mathrm{pg} / \mathrm{mL}$ and $1 \mathrm{ng} / \mathrm{mL}$, respectively.

\subsection{Reverse Transcription Quantitative Real-Time PCR}

Reverse transcription quantitative real-time polymerase chain reaction (RT-qPCR) was performed as before [22]. Briefly, pre-treated HBF RNA was harvested using RNA STAT-60 (AMS Biotechnology, Milton, Abingdon, UK). Approximately $1 \mu \mathrm{g}$ of total HBF RNA was utilized for random-primed reverse transcription using an iScript cDNA synthesis kit (BioRad, Hercules, CA, USA). RT-qPCR was done using iTaq SYBR Green supermix with ROX (Bio-Rad) in an Applied Biosystems 7500 multicolor real-time PCR detection system (Applied Biosystems). The following primer pair sequences were used with glucuronidase $\beta$ (GUSB) serving as a housekeeping gene: GUSB forward (CAGGACCTGCGCACAAGAG), GUSB reverse (AGCGTGTCGACCCCATTC), CXCL8 forward (CTTGGCAGCCTTCCTGATTT), CXCL8 reverse (TTCTTTAGCACTCCTTGGCAAAA), IL6 forward (TGCAGATGAGTACAAAAGTCCTGAT), IL6 reverse (GTGGTTATTGCATCTAGATTCTTTGC). Prior to experimental RT-qPCR, standard curves and primer efficiencies were determined, resulting in the following efficiencies: 93\% (GUSB), 101\% (CXCL8), 95\% (IL6).

\subsection{Western Blot}

Following $30 \mathrm{~min}$ of treatment with eosinophil supernatants with or without inhibitors, HBF were lysed for protein and subsequently subjected to sodium dodecyl sulphatepolyacrylamide gel electrophoresis (SDS-PAGE) and Western blotting, as before [23]. Briefly, cell lysis was done in radioimmune precipitation assay (RIPA), containing $25 \mathrm{mM}$ HEPES (pH 7.5), $150 \mathrm{mM} \mathrm{NaCl}, 1 \%$ Triton X-100, 0.1\% SDS, 2 mM ethylenediaminetetraacetic acid (EDTA), 2 mM egtazic acid (EGTA), 10\% glycerol, $1 \mathrm{mM} \mathrm{NaF}, 200 \mu \mathrm{M}$ sodium orthovanadate, and protease inhibitor mixture (Sigma Aldrich, St. Louis, MO, USA), for 10 min on ice, followed by centrifugation at $21.1 \times g$ for $10 \mathrm{~min}$ at $4{ }^{\circ} \mathrm{C}$. Supernatants were mixed with Laemmli buffer, boiled for $5 \mathrm{~min}$ before being subject to SDS-PAGE and Western blotting against indicated primary and appropriate HRP-conjugated secondary antibodies. Rabbit polyclonal antibody was against pSTAT3 (ab76315 Abcam, Cambridge, UK), while mouse monoclonal antibodies were against NFKB inhibitor $\alpha(\mathrm{IkB} \alpha)$ (MAB4299, R\&D Systems), $\operatorname{IkB} \alpha$ (ab12134, Abcam), phospho-IkB $\alpha$ (MA5-15224, Invitrogen, Carlsbad, CA, USA), and $\beta$-actin (A1978, Sigma Aldrich). Enhanced chemiluminescence (ECL) reaction reagents and GE LAS4000 were used to visualize immunoreactive bands (GE Healthcare, Little Chalfont, UK). Western blot images were linearly adjusted to aid in the visualization of the relevant band. Unadjusted bands were quantified using ImageJ 1.48v [24].

\subsection{Statistical Analyses}

Densitometric Western blot and RT-qPCR data were assessed by representing data as fold of control and utilizing Student's unpaired $t$-test with Bonferroni correction where applicable. Levels of IL6 and IL8 measured by ELISA were compared by log10 transforming the data and analyzing using Student's paired $t$-test. Change in EOS\%, EDN, IL1 $\alpha$ or IL1 $\beta$ 
concentration after (D2) minus before (D0) SBP-Ag measured by ELISA were calculated and a Spearman correlation was used for statistical analyses. Note that EOS\%, EDN, IL1 $\alpha$ and IL1 $\beta$ levels before challenge are typically below $1 \%$ and below detection, respectively.

\section{Results}

3.1. IL6 and IL8 Secretion from HBF Treated with Eosinophil-Derived Supernatants Is Dependent on the IL1 Receptor

As a first approach, we sought to explore the potential role of IL1 family cytokines in mediating fibroblast responses from factors released by eosinophils. We have previously identified the release of IL1 $\beta$ from activated eosinophils $[25,26]$, which could account for paracrine signaling in the asthmatic airway. In addition, previous transcriptomic data of the response of lung fibroblasts to eosinophil-derived soluble mediators (using the same methodology) followed by pathway analysis suggested that IL1 signaling was a potential upstream mediator of fibroblast responses [7]. To determine if IL1 drives fibroblast responses to eosinophil-derived soluble mediators, we first utilized the IL1 receptor antagonist (IL1RA), the competitive endogenous protein inhibitor of the IL1R. As shown in Figure 1A,B and as previously reported, there is marked induction of IL8 and IL6 secretion by airway fibroblasts in response to treatment with supernatants from degranulating eosinophils, as determined by ELISA. Of note, we have previously demonstrated that eosinophil supernatants do not contain elevated amounts of IL6 or IL8 [6]. HBF treatment with IL1RA $30 \mathrm{~min}$ prior to stimulation with eosinophil-derived supernatants results in a marked attenuation of IL8 and IL6 protein release (Figure 1A,B), suggesting that either expression or secretion of these two cytokines is dependent on IL1 signaling. We then examined the effect of IL1RA inhibition on HBF-induced CXCL8 and IL6 transcription by eosinophilderived products. We observed a marked attenuation in the mRNA transcripts for both genes (Figure 1C,D), indicating that signaling via IL1R is essential for the transcriptional upregulation of these two genes in response to eosinophil-derived mediators.

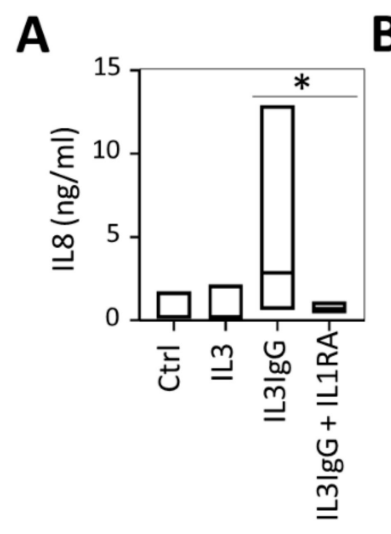

B

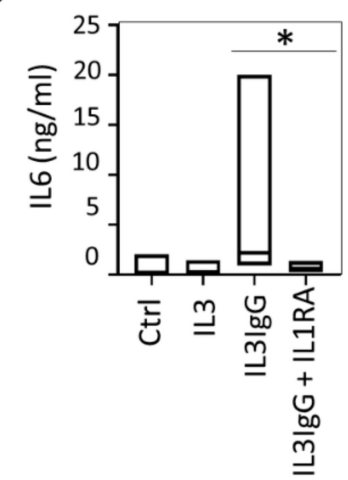

C

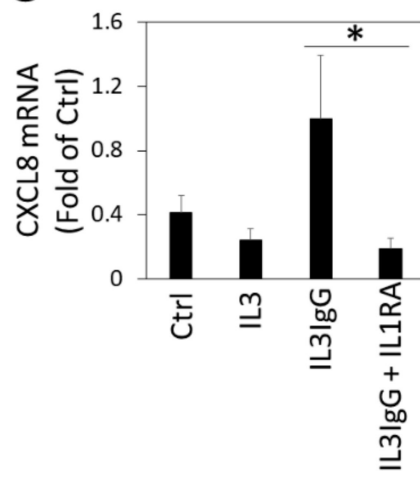

D

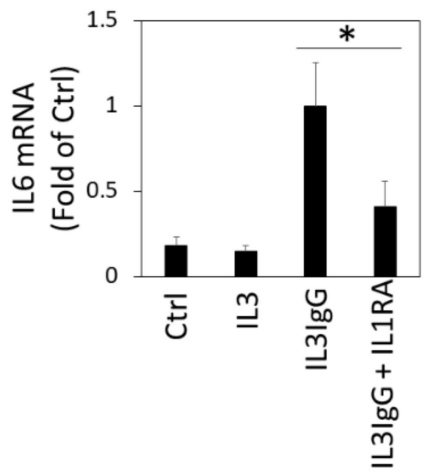

Figure 1. Interleukin 6 (IL6) and IL8 expression and secretion by human bronchial fibroblasts stimulated with eosinophilderived soluble mediators requires signaling via the IL1 receptor. Human bronchial fibroblasts (HBF) were incubated with IL1 receptor antagonist (IL1RA, $100 \mathrm{ng} / \mathrm{mL})$ or vehicle $(0.1 \%$ bovine serum albumin (BSA) in PBS) for $30 \mathrm{~min}$, and subsequently stimulated with eosinophil supernatants (IL3 or IL3IgG) or basal medium (Ctrl). Twenty-four hours later, HBF supernatants were analyzed via ELISA for levels of IL8 (A) and IL6 (B) ( $n=8$ for all conditions), and paired Student's $t$-test was used to test for statistical significance $\left({ }^{*} p<0.05\right)$. HBF lysates were analyzed for mRNA levels of CXCL8 (C) and IL6 (D) via RT-qPCR ( $n=3$ for all conditions) and analyzed by setting IL3IgG as a reference (mean \pm sd) and using unpaired Student's $t$-test to test for statistical significance $\left({ }^{*} p<0.05\right)$.

\subsection{IL1 3 Is Dispensable for the Induction of IL6/IL8 in HBF Treated with Eosinophil-Derived Supernatants}

Because IL1 $\beta$ can be released by activated eosinophils $[25,26]$, we tested whether IL1 $\beta$ may be the primary agonist of the IL1 receptor in this context. As shown in Figure A1 $(1,2)$, the maximal response of the HBF release of IL6 or IL8 to recombinant (r)IL1 $\beta$ stimulation 
occurs at $1 \mathrm{ng} / \mathrm{mL}$ (55 $\mathrm{pM}$ ). To do so, we first validated the inhibitory capacity and specificity of the neutralizing anti-IL1 $\beta$ antibody (clone $4 \mathrm{H} 5$, InvivoGen) from $10 \mathrm{ng} / \mathrm{mL}$ (68 $\mathrm{pM}$, equimolar) to $10 \mu \mathrm{g} / \mathrm{mL}(\sim 1000$-fold molar excess of anti-IL1 $\beta$ neutralizing antibody). Incubation of the anti-IL1 $\beta$ neutralizing antibody (or isotype control IgG) with $1 \mathrm{ng} / \mathrm{mL}$ rIL1 $\beta$ for $1 \mathrm{~h}$ prior to stimulation results in a dose-dependent blockade of IL 6 and IL8 release by HBF compared to IgG control antibodies (Figure A2 $(1,2)$ ), suggesting that this antibody is effective in blocking IL1 $\beta$ effects. Likewise, this antibody does not block rIL1 $\alpha-$ induced effects, confirming the specificity of the blockade (figure not shown). We then utilized the antibody, at a previously optimized concentration of $1 \mu \mathrm{g} / \mathrm{mL}$, to determine the role of IL1 $\beta$ in eosinophil supernatant-mediated stimulation of airway fibroblasts. As shown in Figure 2, incubation of the IL1 $\beta$ antibody with eosinophil supernatants for $1 \mathrm{~h}$ prior to stimulation does not attenuate IL8 or IL6 secretion by airway fibroblasts.

A

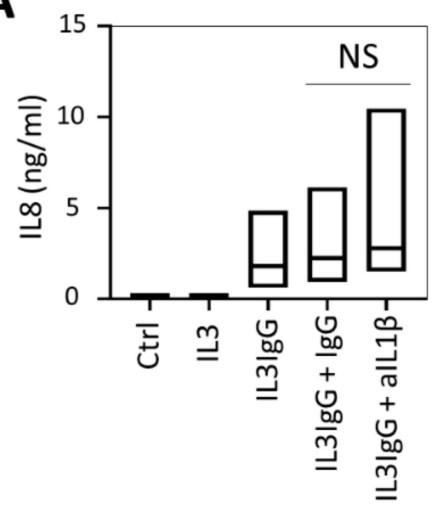

B

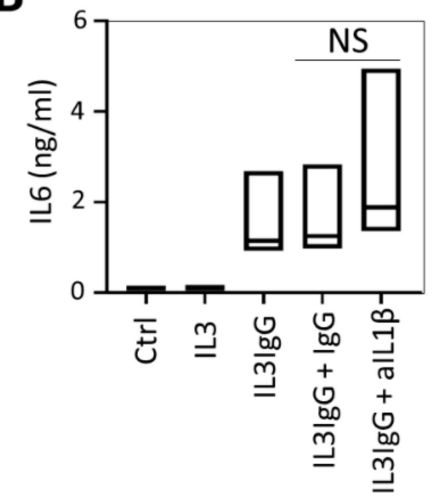

Figure 2. Release of IL6 and IL8 by human bronchial fibroblasts stimulated with products from activated eosinophils is independent of IL1 $\beta$. HBF were stimulated with eosinophil supernatants (IL3 or IL3IgG) or basal medium (Ctrl). IL3IgG eosinophil supernatants were incubated for $1 \mathrm{~h}$ with IgG control antibody $(1 \mu \mathrm{g} / \mathrm{mL})$ or IL1 $\beta$ neutralizing antibody ( $\operatorname{IL} 1 \beta, 1 \mu \mathrm{g} / \mathrm{mL}$ ) prior to stimulation, as indicated. Twenty-four hours later, HBF supernatants were tested for IL8 (A) and IL6 (B) via ELISA ( $n=4$ for all conditions). Paired Student's $t$-test was used to test for statistically significant differences (NS = not significant).

\subsection{IL1 $\alpha$ Is Essential for the Induction of IL6/IL8 in HBF Treated with Eosinophil-Derived Supernatants}

Considering that the blockade of IL1R, but not the neutralization of IL1 $\beta$ agonist, results in significant inhibition of IL6 and IL8 release, we sought to examine whether IL1 $\alpha$ was the primary agonist signaling via the IL1R in HBF. As with IL1 $\beta$, we first established the optimal concentration of the rIL1 $\alpha$ agonist to be $1 \mathrm{ng} / \mathrm{mL}$ (Figure A1(3,4)) and then validated the anti-IL1 $\alpha$ antibody (clone 7D4), observing that it is capable of blocking the rIL1 $\alpha$-dependent release of IL6 and IL8 by HBF in a dose-dependent manner (Figure A2(3,4)). Similar to IL1 $\beta$, we chose $1 \mu \mathrm{g} / \mathrm{mL}$ (6.8 nM, 124-fold molar excess) as the optimized blocking dose. Additionally, IL1 $\alpha$ neutralizing antibody has no effect on rIL1 $\beta$-induced IL6 and IL8 expression (Figure A3). Subsequently, we employed $1 \mu \mathrm{g} / \mathrm{mL}$ of IL1 $\alpha$ neutralizing antibody to examine its ability to disrupt HBF pro-inflammatory activation. We found that treatment of IL3IgG-activated eosinophil supernatants with the anti-IL $1 \alpha$ neutralizing antibody for $1 \mathrm{~h}$ prior to incubation with HBF markedly reduces the ability of these cells to release both IL6 and IL8 (Figure 3). These data suggest that eosinophil lysis products lead to a release of IL6 and IL8 through activation by IL1 $\alpha$.

\subsection{IL1 $(\alpha / \beta)$ Is Associated with Eosinophilic Inflammation after SBP-Ag}

In light of these observations indicating that IL $1 \alpha$ is playing a role in the activation of $\mathrm{HBF}$ to release pro-inflammatory mediators in vitro, we were interested in examining the relationship between IL $1 \alpha$ and eosinophil activation in an in vivo model of allergic 
inflammation, such as that seen in asthma. For this, we utilized BAL samples collected from patients with mild allergic asthma who underwent SBP-Ag (see supplemental Table A1 in Appendix D and [21] for patient characterization). In this human model of allergic inflammation, BAL eosinophils represent less than 1\% of total BAL cells prior to SBP-Ag (baseline, D0), but markedly increase $48 \mathrm{~h}$ later $[19,27]$. In these samples, we now find that the levels of IL1 $\alpha$ are undetectable in most patients (17 out of 18) on D0. Forty-eight $h$ after SBP-Ag challenge, the levels of IL1 $\alpha$ markedly increase in the BAL fluids of subjects with the most response to the allergen (as determined by the eosinophil \%), demonstrating a correlation between the presence of IL1 $\alpha$ and \% eosinophils detected in the BAL (Figure 4A). We also observed a similar correlation between IL1 $\beta$ and BAL eosinophils \% (Figure 4B). Furthermore, when we assayed the amount of eosinophil-derived neurotoxin (EDN), a marker of eosinophil degranulation, we found correlation with IL1 $\alpha$ and IL1 $\beta$ levels (Figure 4C,D). This suggests that increases in eosinophilic inflammation and degranulation are associated with increases in IL $1 \alpha$, providing an in vivo relevant link to the IL1 $\alpha$ dependent effects that we observed in fibroblasts in vitro. Changes in \% of the other cell types counted in the BAL fluids (macrophages, neutrophils and lymphocytes; supplemental Table A2 in Appendix E) did not display correlation with either IL1 $\alpha$ or IL1 $\beta$ (not shown).
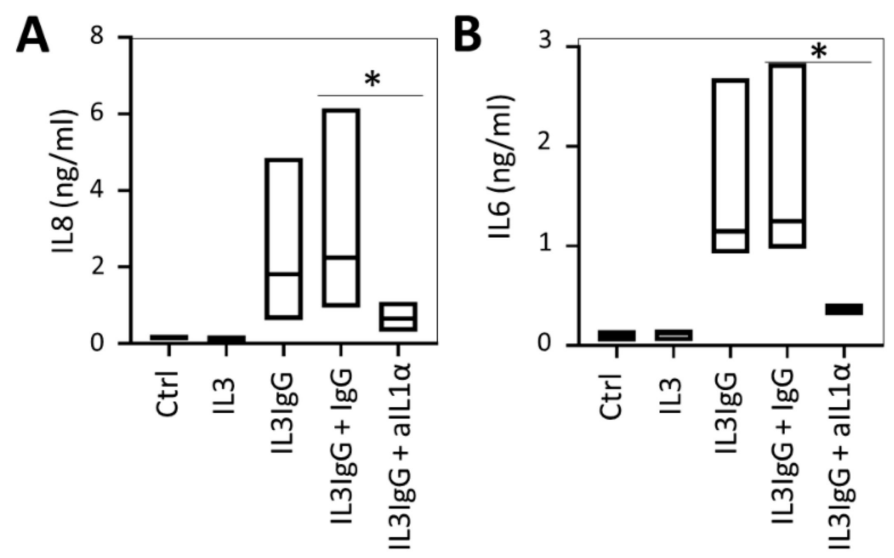

Figure 3. Release of IL6 and IL8 by human bronchial fibroblasts stimulated with eosinophil soluble mediators is dependent on activation by IL1 $\alpha$. HBF were stimulated with eosinophil supernatants (IL3 or IL3IgG) or basal medium (Ctrl). IL3IgG supernatants were incubated for $1 \mathrm{~h}$ with either IgG control antibody $(1 \mu \mathrm{g} / \mathrm{mL}$ ) or IL1 $\alpha$ neutralizing antibody (aIL $1 \alpha, 1 \mu \mathrm{g} / \mathrm{mL}$ ) prior to stimulation, as indicated. Twenty-four hours later, HBF supernatants were collected, and IL8 (A) and IL6 (B) levels were analyzed via ELISA ( $n=4$ for all conditions). Paired Student's $t$-test was used to test for statistically significant differences $\left({ }^{*} p<0.05\right)$.

\subsection{Release of IL6 in HBF Stimulated with Eosinophil-Derived Supernatants Is Dependent on NFkB Signaling}

Because IL1 $\alpha$ signals canonically via the IL1R through IL1 receptor-associated kinase 1 (IRAK1), MyD88 and nuclear factor kappa-light-chain-enhancer of activated B cells $(\mathrm{NF} K \mathrm{~B})$ signaling, we then sought to examine the activation of this pathway by eosinophilderived supernatants. As show in Figure 5, the treatment of airway fibroblasts with eosinophil-derived supernatants induces $I \kappa \mathrm{B} \alpha$ phosphorylation at Ser 32/36 residues and the degradation of $I \kappa B \alpha$, indicating activation of I $\kappa$ B kinase (Ikk) and release of Rel65 and Rel50 (NFkB) for nuclear translocation. This indicates that, at $30 \mathrm{~min}$, there is activation of NFKB signaling in HBF by eosinophil-derived supernatants. When eosinophil supernatants were incubated with IL1 $\alpha$ (but not IL1 $\beta$ ) neutralizing antibody prior to stimulation, I $\kappa \mathrm{B} \alpha$ phosphorylation was inhibited in HBF (Figure 5A,B), suggesting that the activation of $\mathrm{NF}_{\kappa} \mathrm{B}$ by eosinophil supernatants is dependent on IL1 $\alpha$. Consistent with this finding, the blockade of NFKB signaling by the IкB kinase inhibitor, BMS-345541, strongly attenuated IL6 secretion by HBF in response to eosinophil-derived supernatants (Figure 5C), establishing the requirement for NFkB signaling in IL6 induction. 

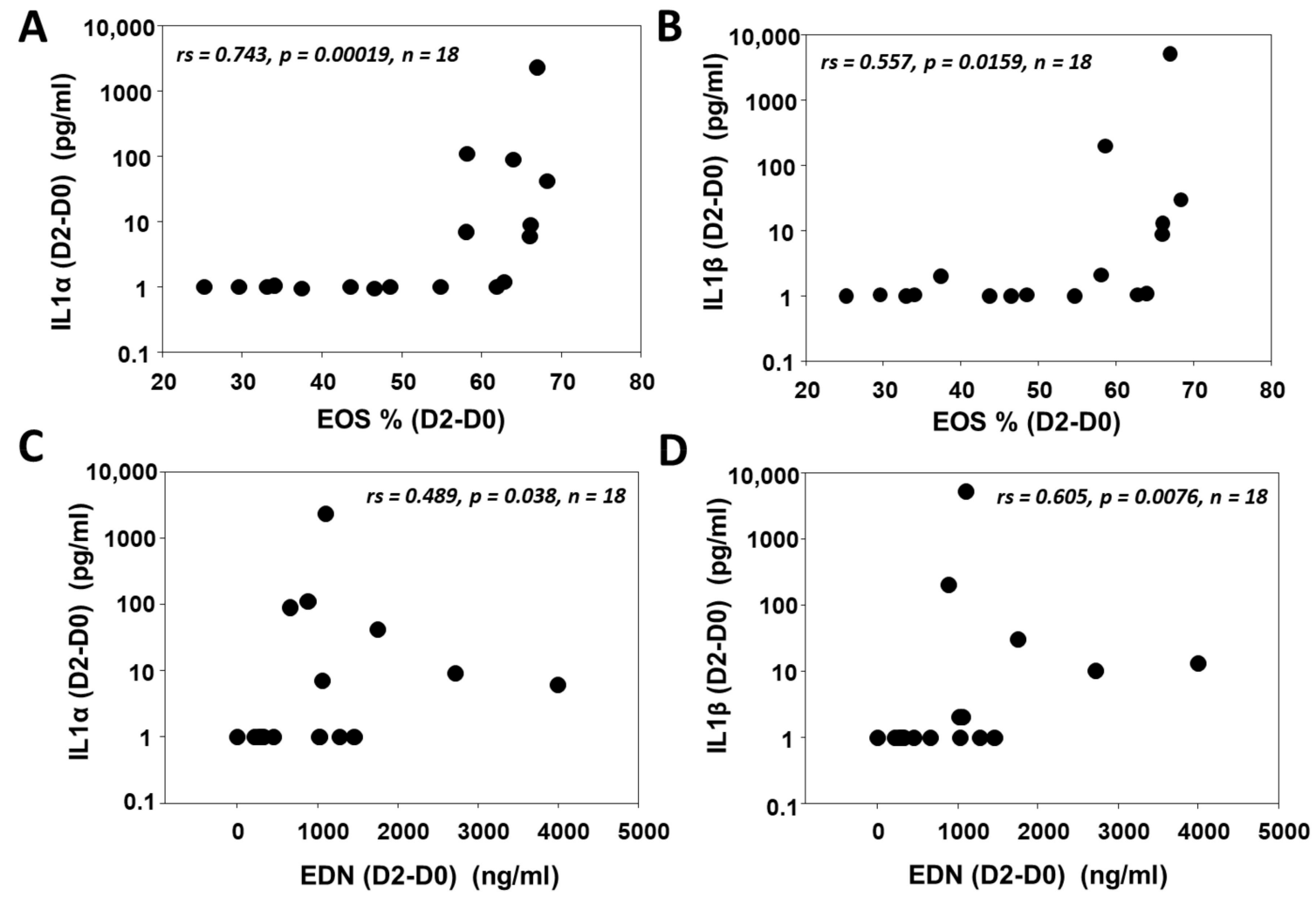

Figure 4. Eosinophilic inflammation is associated with IL1 $\alpha$ and IL1 $\beta$ in bronchoalveolar lavage (BAL) after a segmental allergen challenge in allergic patients with mild asthma. ELISA against IL1 $\alpha(\mathbf{A}, \mathbf{C}), \operatorname{IL1} \beta(\mathbf{B}, \mathbf{D})$ and eosinophil-derived neurotoxin (EDN) (C,D), as well as the quantification of purified eosinophils (A,B), was performed from BAL samples before segmental allergen challenge (SBP-Ag) (D0) and $48 \mathrm{~h}$ after the challenge (D2) (paired values from $n=18$ subjects). Changes from D0 to D2 are presented for all variables. Spearman correlation was utilized for statistical analysis.

A

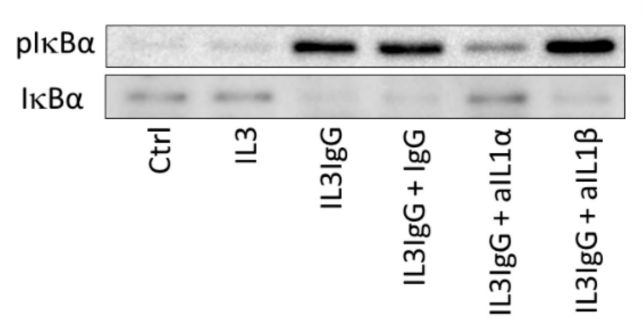

B

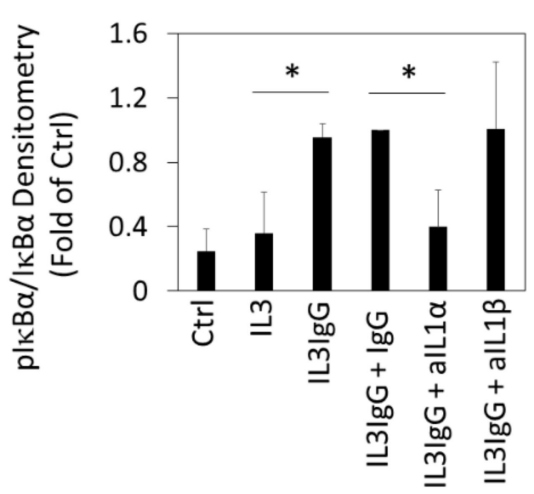

C

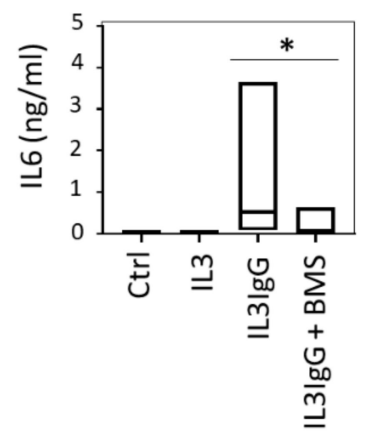

Figure 5. Eosinophil lysis products induce the production of IL6 by human bronchial fibroblasts through the IL1 $\alpha$-dependent nuclear factor kappa-light-chain-enhancer of activated B cell (NFKB) signaling mechanism. (A) IL3IgG supernatants were incubated for $1 \mathrm{~h}$ with either IgG control antibody $(1 \mu \mathrm{g} / \mathrm{mL})$, IL1 $\alpha$ neutralizing antibody (aIL1 $\alpha, 1 \mu \mathrm{g} / \mathrm{mL})$ or IL1 $\beta$ neutralizing antibody (aIL1 $\beta, 1 \mu \mathrm{g} / \mathrm{mL})$ prior to stimulation of HBF. HBF were alternatively incubated with basal medium (Ctrl), IL3 or IL3IgG eosinophil supernatants as a control. Thirty minutes after stimulation, HBF protein lysates were obtained and subjected to SDS-PAGE and Western blotting with indicated antibodies. (B) Densitometry of Western blots from A. ( $n=3$ for all conditions) was done in ImageJ (mean $\pm \mathrm{sd}$ ) and analyzed by unpaired Student's $t$-test with Bonferroni correction to determine statistically significant differences $\left({ }^{*} p<0.025\right)$. (C) HBF were treated with IkB kinase inhibitor $(10$ $\mu \mathrm{M}$ BMS-345541 (BMS)) or vehicle (dimethyl sulfoxide (DMSO)) prior to stimulation with eosinophil supernatants for $24 \mathrm{~h}$. HBF supernatants were collected ( $n=7$ for all conditions) and levels of IL6 were determined via ELISA. Paired Student's $t$-test was used to test for statistically significant differences $\left({ }^{*} p<0.05\right)$. 


\subsection{IL6 Expression by HBF Requires Janus Kinase (JAK)/Signal Transducer and Activator of Transcription Protein (STAT) Signaling}

We also observed the induction of STAT3 by eosinophil supernatants (Figure 6A). However, incubation with IL1 $\alpha$ and IL1 $\beta$ neutralizing antibodies did not affect phosphorylation of STAT3 (Figure 6A,B). Nevertheless, inhibition of eosinophil supernatantinduced JAK/STAT signaling (and $p$-STAT3) by the JAK inhibitor ruxolitinib prevented IL6 transcription and secretion (Figure 6C,D). This suggests that a co-operative, second IL1 $\alpha$-independent signal is required for full activation of the IL6 gene locus. We did not see similar inhibition of inducible IL8 in HBF (data not shown).
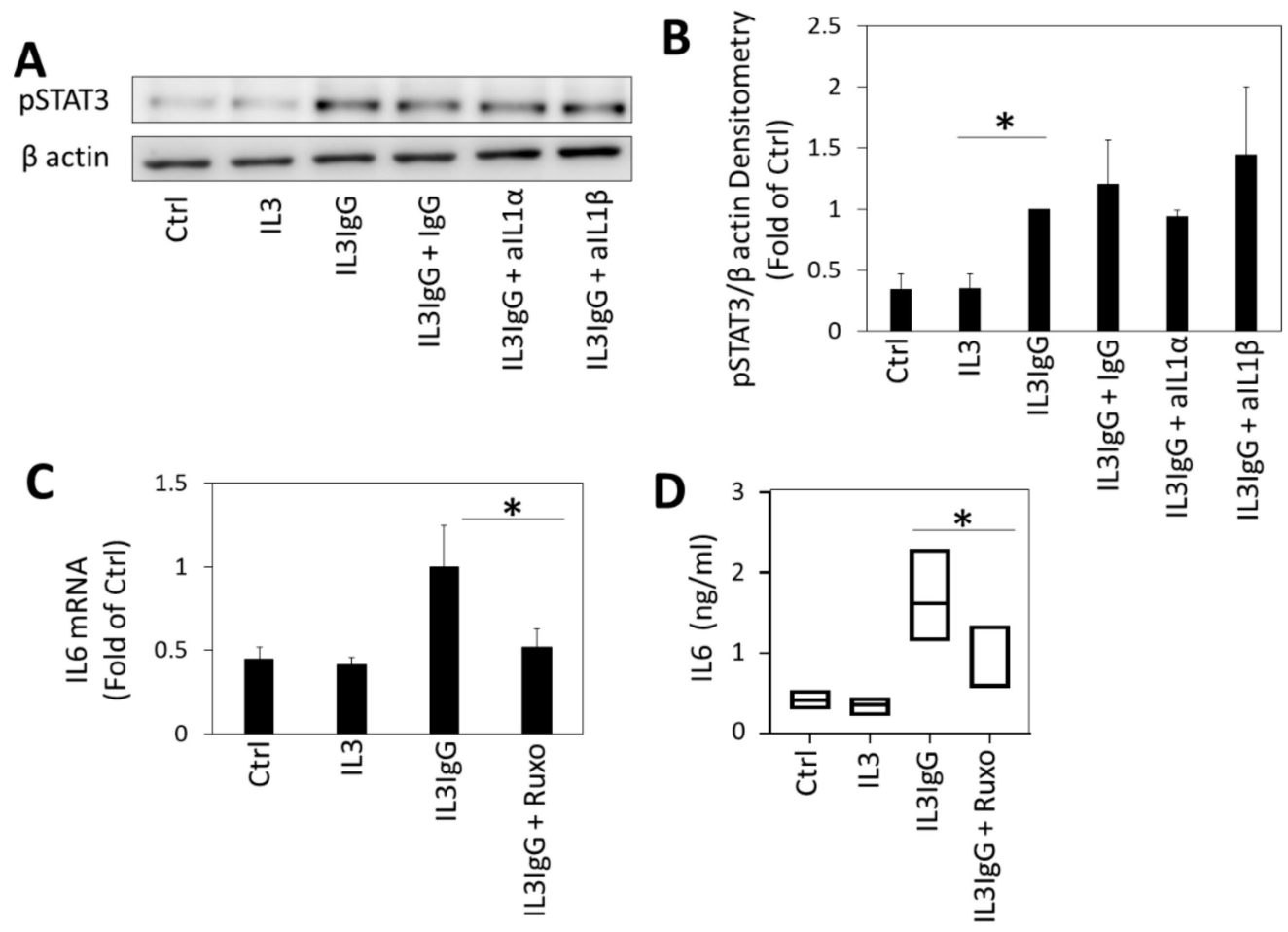

Figure 6. Eosinophil-derived supernatants lead to the production of IL6 by HBF through the IL1independent Janus Kinase (JAK)/Signal Transducer and Activator of Transcription Protein (STAT) signaling mechanism. (A) IL3IgG supernatants were incubated for $1 \mathrm{~h}$ with either IgG control antibody $(1 \mu \mathrm{g} / \mathrm{mL})$, IL1 $\alpha$ neutralizing antibody (aIL1 $\alpha, 1 \mu \mathrm{g} / \mathrm{mL}$ ) or IL1 $\beta$ neutralizing antibody $(\mathrm{aIL} 1 \beta, 1 \mu \mathrm{g} / \mathrm{mL}$ ) prior to stimulation of HBF. HBF were alternatively incubated with basal medium (Ctrl), IL3 or IL3IgG eosinophil supernatants as a control. Thirty minutes after stimulation, HBF protein lysates were obtained and subjected to SDS-PAGE and Western blotting with indicated antibodies. (B) Densitometry of Western blots from A. ( $n=3$ for all conditions) was done in ImageJ (mean $\pm \mathrm{sd}$ ). C-D. HBF were treated with Janus-associated kinase (JAK) inhibitor (100 nM ruxolitinib (Ruxo)) or vehicle (ethanol) prior to stimulation with eosinophil supernatants for $24 \mathrm{~h}$. mRNA levels of IL6 in HBF ( $n=3$ for all conditions) were assessed via RT-qPCR (C). Levels of IL6 in HBF supernatant ( $n=3$ for all conditions) were assessed via ELISA (D). Unpaired (B,C) or paired (D) Student's $t$-test was used to test for statistically significant differences $\left({ }^{*} p<0.05\right)$.

\subsection{Src-Dependent Signaling Is Required for IL8 Expression by HBF in Response to} Eosinophil-Derived Supernatants, While NFKB Is Dispensable

In addition to releasing IL6, HBF activated by soluble mediators from IL3IgG-stimulated eosinophils also secrete high levels of pro-neutrophilic and pro-inflammatory cytokine IL8. However, when we tried to inhibit eosinophil supernatant-induced IL8 in HBF via the blockade of NFKB signaling with BMS-345541, there was no effect (Figure 7A). This suggested that IL1 $\alpha$ uses an alternative signaling pathway to induce IL8 gene expression. Considering that proto-oncogene tyrosine-protein kinase Src has previously been reported 
to signal downstream of IL1 $\beta$ to lead to IL8 expression [28], we hypothesized that this kinase plays a role in the secretion of IL8 by eosinophil soluble mediator activated-HBF. Our data demonstrate that treatment with PP2, selective inhibitor of Src-family kinases, disrupts the ability of activated HBF to release IL8, when compared to the inactive, analogous small molecule, PP3 (Figure 7B) and that this effect is transcriptionally regulated (Figure 7C). Interestingly, treatment with PP2 did not disrupt IL6 secretion under the same conditions (Figure 7D). Our data demonstrate that HBF stimulated by soluble mediators from IL3IgGactivated eosinophils release IL8 through the Src-family kinases-mediated signaling, in contrast to the NFKB and JAK/STAT signaling required for IL6.
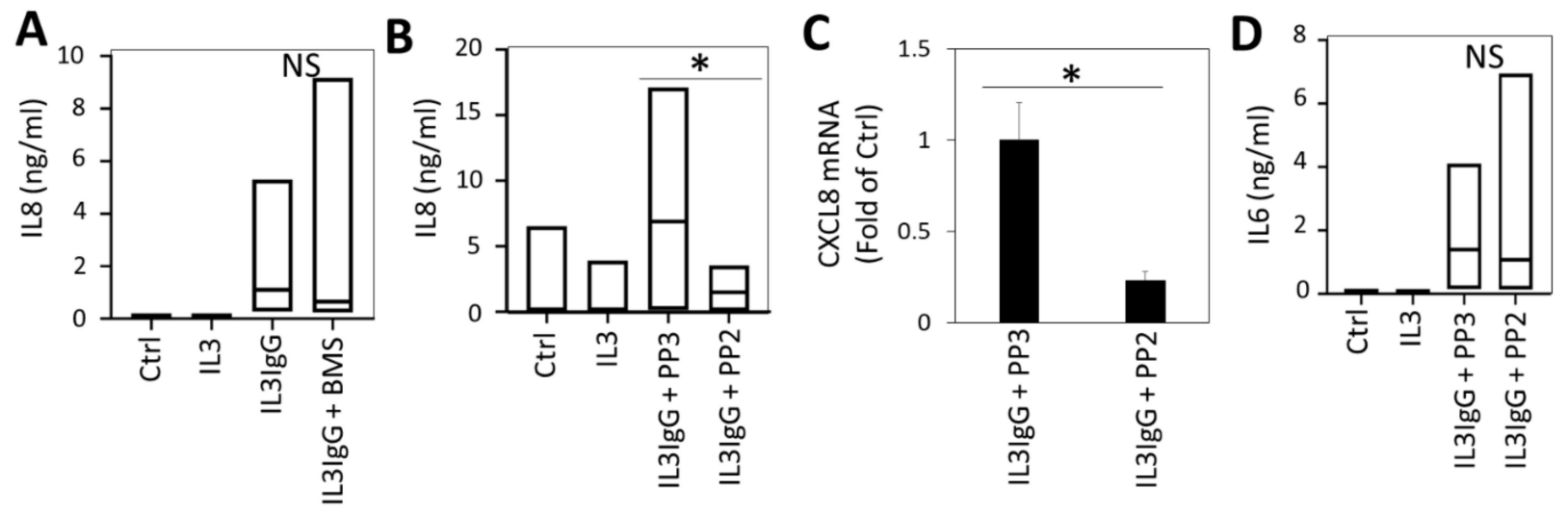

Figure 7. Eosinophil lysis products lead to the release of IL8 by human bronchial fibroblasts through the Src family kinase signaling mechanism. HBF were treated with IкB kinase inhibitor (10 $\mu \mathrm{M}$ BMS-345541 (BMS)), or vehicle (DMSO) (A), or inhibitor of Src-family kinases (10 $\mu \mathrm{M}$ PP2 (or PP3 control)) (B-D) prior to stimulation with eosinophil supernatants. Twenty-four hours later, HBF lysates were assessed for levels of IL8 or IL6 ( $n=7$ for all conditions in A; $n=3$ for Ctrl and IL3 conditions and $n=4$ for IL3IgG + PP3 and IL3IgG + PP2 conditions in (B,D)) via ELISA (A-D). At the same time point, mRNA levels of CXCL8 in HBF ( $n=3$ for all conditions) were assessed via RT-qPCR (mean $\pm \mathrm{sd}$ ). Paired (A-D) or unpaired (C) Student's $t$-test was used to test for statistically significant differences $\left.{ }^{*} p<0.05\right)$.

\section{Discussion}

In this study, our primary observation is that the blockade of IL $1 \alpha$ is sufficient to prevent the induction of IL6 and IL8 expression in HBF by eosinophil-derived soluble mediators and is associated with eosinophilic inflammation in human airways after antigen challenge. This finding suggests that IL $1 \alpha$ is a key component of the milieu of soluble mediators released upon eosinophil degranulation and cytolysis that drives pro-inflammatory signaling in bronchial fibroblasts.

Interleukin-1 family cytokines play an important role in both the innate and adaptive immune response and are implicated in eosinophilic inflammation and airway remodeling $[25,29]$. The IL1 receptor is bound by both and IL1 $\alpha$ and IL1 $\beta$, with similar downstream signaling responses. IL $1 \alpha$ is expressed ubiquitously in many immune and structural cells [30] and acts as an alarmin. Activated eosinophils have also been found to express IL1 $\alpha$ [31]. In contrast, IL1 $\beta$ has a more limited expression, mainly in immune cells, including our findings that it is expressed in stimulated eosinophils $[25,26]$. Thus, it is somewhat surprising that we have observed that IL $1 \alpha$, rather than IL1 $\beta$, appears to be the key ligand in the activation of bronchial fibroblasts incubated with eosinophil-derived soluble mediators. However, IL $1 \alpha$ has a role in the induction of sterile inflammation from necrotic cells, including neutrophils [32]. Thus, it is intriguing to speculate that activated eosinophils undergoing cytolysis may also be a source of IL $1 \alpha$, which then can signal to other cellular compartments in the allergically-inflamed airway. For example, it is known that IL1 $\alpha$ co-localizes with nuclear material, and extracellular nuclear contents, including DNA, have been found in association with eosinophilic inflammation [33,34]. Although IL1 $\alpha$ can induce neutrophil recruitment in other contexts, we previously found that eosinophil- 
derived supernatants did not induce neutrophil chemotaxis [6]. Rather, in this context, it appears that eosinophil-derived IL1 $\alpha$ may only play a role in neutrophil chemotaxis via the induction of bronchial fibroblast-derived IL8, which we have found in sufficient quantities to recruit neutrophils [6]. Transduction of immune signals via the mesenchyme is increasingly recognized as an important component of a variety of inflammatory disorders and contributes to tissue remodeling $[35,36]$. In other contexts, IL1 $\alpha$ has been shown to signal to mesenchymal cells with subsequent release of pro-neutrophilic signals [37].

To determine the potential in vivo relevance of this finding, we utilized segmental antigen bronchoprovocation, a powerful tool to interrogate the mechanism of allergic inflammation in the in vivo context [38]. Using BAL samples obtained from Day 0 (just prior to antigen challenge) versus Day 2 (two days after antigen challenge), a time characterized by intense eosinophilic inflammation, we found a compelling correlation between IL1 $\alpha$ levels and eosinophilic inflammation. This finding supports the plausibility of IL $1 \alpha$ as a component of the inflammatory milieu of the allergic airway. While the cellular source of IL1 $\alpha$ cannot be discerned from these experiments, combined with our ex vivo investigations, it seems that, in addition to other known sources of this cytokine [30], IL1 $\alpha$ may originate in part from eosinophilic cytolysis and degranulation. However, given that expression or release of IL $1 \alpha$ in an autocrine fashion can be induced by IL1 family cytokines or other agonists [39-41], we cannot completely exclude that the source of IL1 $\alpha$ is from HBF. However, this possibility appears unlikely due to the ability of IL1 $\alpha$ neutralizing antibody to inhibit eosinophil soluble factor-mediated NFKB signaling within $30 \mathrm{~min}$ of activation.

A second key conclusion of this study is that IL1 $\alpha$ signals via the IL1R and NFKB to induce IL6 expression and secretion in HBF, but uses alternative, NFKB-independent signaling to induce IL8. IL1 family cytokines signal through the IL1 receptor (IL1R), a member of the IL1/Toll-like receptor superfamily. IL1R has a Toll-IL1R (TIR) domain, which couples the receptor to MyD88 and IL1 receptor-associated kinase (IRAK), mediating downstream activation of IKB kinase (Ikk), phosphorylation of IKB (followed by ubiquitination/degradation) and activation of NFKB. We have found that there is activation of NFKB signaling by eosinophil supernatants, consistent with activation of IL1R. Furthermore, blockade of IL $1 \alpha$ inhibited this activation, confirming the role of IL1 $\alpha$ in its activation. Finally, IL6 expression in HBF stimulated with eosinophil supernatants is dependent on NFKB activation based on the use of a small molecule inhibitor of Ikk. Interestingly, downstream signaling to IL6 and IL8 activation seems to diverge in this model, with canonical NFKB signaling only required for IL6 activation. For example, we additionally found that Src was required for the expression of IL8 in HBF in response to eosinophil soluble mediators, whereas $\mathrm{NF}_{\mathrm{K} B} \mathrm{~B}$ was dispensable for its activation. IL1 cytokines, in particular IL1 $\beta$, have been reported to activate Src signaling in other contexts and cell types [28]. This suggests that it is possible that IL1 $\alpha$ uses signaling via Src to induce IL8 expression and secretion, although we cannot exclude activation via an alternative agonist in the eosinophil-derived supernatants. Finally, we also observed dependency of IL6 on JAK/STAT signaling, indicating that co-operative signaling from other non-IL1 $\alpha$ ligands is at play in the induction of IL6.

A potential strength of our approach is the use of well-characterized eosinophil cultures from humans. The fidelity of the IL3-induced phenotype to airway eosinophils is well established, making them a highly relevant tool to understand the behavior and influence of eosinophils in airway inflammation and remodeling. Secondly, we have coupled these cells with primary cultures of bronchial fibroblasts. While limitations of primary fibroblast culture are understood, we feel that this is a relevant model to study signaling interactions and enable mechanistic investigations. We acknowledge that these studies are performed using an ex vivo system that may not recapitulate the findings in vivo. However, to address this limitation we did examine the correlation between IL1 $\alpha$ and eosinophilic inflammation in the segmental antigen challenge model of human allergic airway inflammation. 
Follow-on studies to isolate BAL eosinophils in the allergically inflamed airway, followed by induction of cytolysis and examination of the IL1 $\alpha$ dependency of the effect could also further support its role in in vivo allergic inflammation. Additional studies are needed to further define the mechanism through which IL1R-mediated signaling controls the release of IL8 and the mode of co-operation between NFKB and JAK/STAT signaling leading to the release of IL6 in fibroblasts activated by eosinophil soluble mediators.

\section{Conclusions}

In conclusion, we have found that IL1 $\alpha$ appears to be a critical component of the soluble eosinophil-derived milieu that drives pro-inflammatory bronchial fibroblast responses and is associated with eosinophilic inflammation in the human airway following SBP-Ag. Further, we identified that IL1 $\alpha$-dependent NFKB signaling works in tandem with JAK/STAT and Src to induce the release of IL6 and IL8 from HBF. Taken together, these data suggest an important role for IL $1 \alpha$ in mediating paracrine signals from eosinophils undergoing cytolysis in the allergic asthmatic airway. Disrupting these downstream signaling intermediates could be a strategy to mitigate the airway remodeling effects of eosinophilic inflammation.

Author Contributions: Conceptualization, N.S., S.E., N.N.J., K.B.; methodology, N.S., S.E., K.B.; software, N/A; validation, K.B., J.P.L., H.F., A.L.N., S.E.; formal analysis, K.B., N.S., S.E.; investigation, K.B., S.E., J.P.L., H.F., A.L.N., E.M.B., I.S.M.; resources, J.P.L., H.F., A.L.N., K.B., E.M.B.; data curation, K.B., S.E., N.S.; writing-original draft preparation, K.B.; writing-review and editing, K.B., H.F., A.L.N., E.M.B., I.S.M., N.S., S.E., N.N.J.; visualization, K.B., S.E.; supervision, N.S.; project administration, K.B.; funding acquisition, N.S., N.N.J., S.E., K.B. All authors have read and agreed to the published version of the manuscript.

Funding: This work was supported by NIH HL088594 (N.N.J.), NIH HL136795 (N.S.), NIH HL146402 (N.S.).

Institutional Review Board Statement: This study was conducted according to the guidelines of the Declaration of Helsinki, and approved by the Institutional Re-view Board of University of Wisconsin-Madison (IRB\#2013-1570, IRB\#1999-292).

Informed Consent Statement: Informed consent was obtained from all subjects involved in the study.

Data Availability Statement: No data included in this manuscript have been placed in a public repository. Data can be made available upon request to the corresponding author.

Acknowledgments: We gratefully acknowledge Elizabeth McKernan, and Paul Fichtinger, of the UWMadison Eosinophil Core facility (P.I. Sameer Mathur) for blood eosinophil purification, the research nurse co-ordinators in the UW-Madison Clinical Core facility (P.I. Loren Denlinger) for subject recruitment and screening, and Elizabeth Kelly for preparing fibroblasts from bronchial biopsies.

Conflicts of Interest: Nizar N. Jarjour has received consulting fees from Glaxo Smith Kline, Astra Zeneca, and Boehringer Ingelheim over the past three years. The remaining authors declare no conflict of interest. 


\section{Appendix A}

1

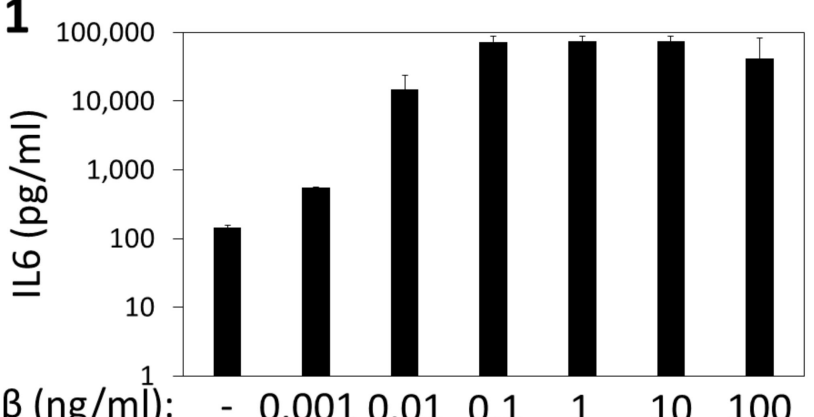

3

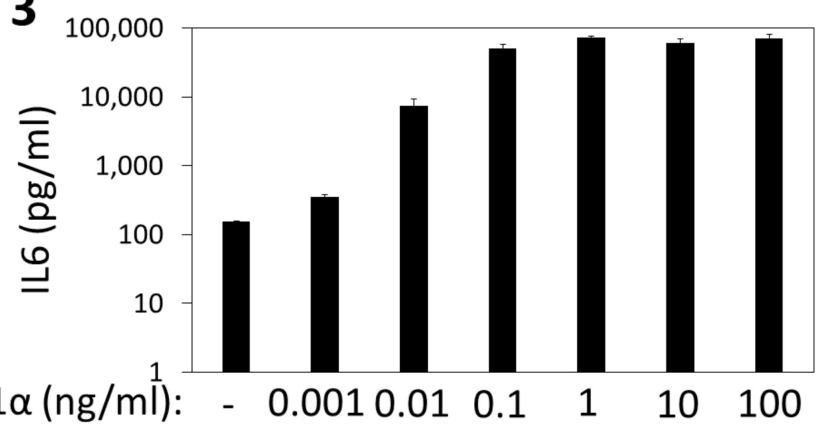

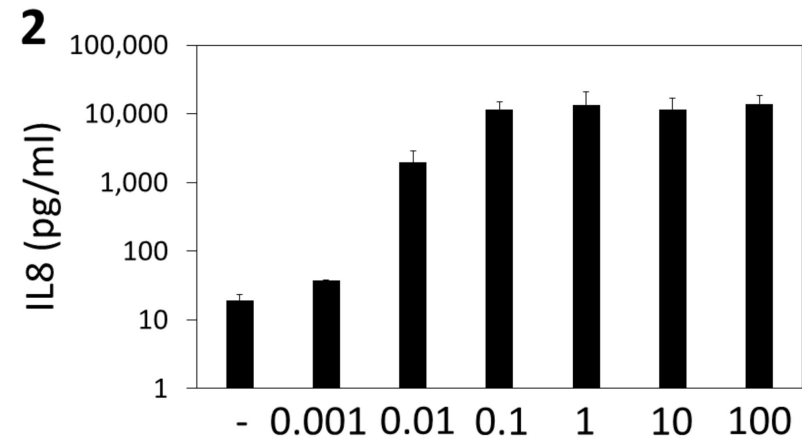

4

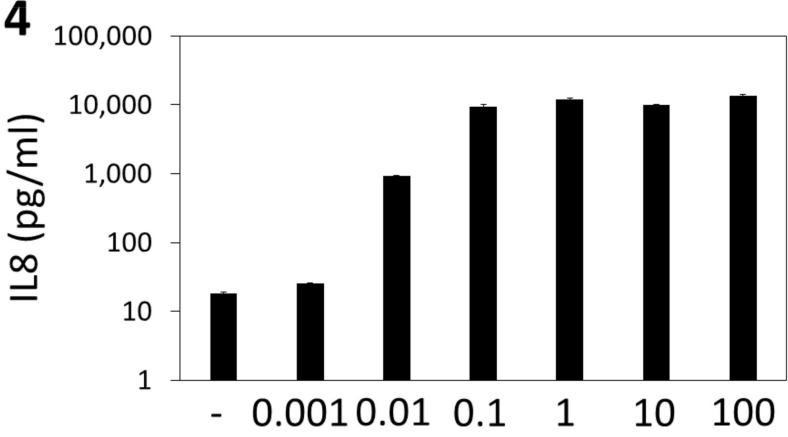

Figure A1. Dose response to recombinant IL1 $\beta$ and IL1 $\alpha$ in human bronchial fibroblasts. Primary culture HBF were treated for $24 \mathrm{~h}$ with recombinant $(\mathrm{r}) \operatorname{IL} 1 \beta(\mathbf{1}, \mathbf{2})$ or $\operatorname{rIL} 1 \alpha(3,4)$ using concentrations indicated in the figure. HBF supernatants were collected and release of IL6 and IL8 was analyzed via ELISA ( $n=2$ technical replicates).

Appendix B

1

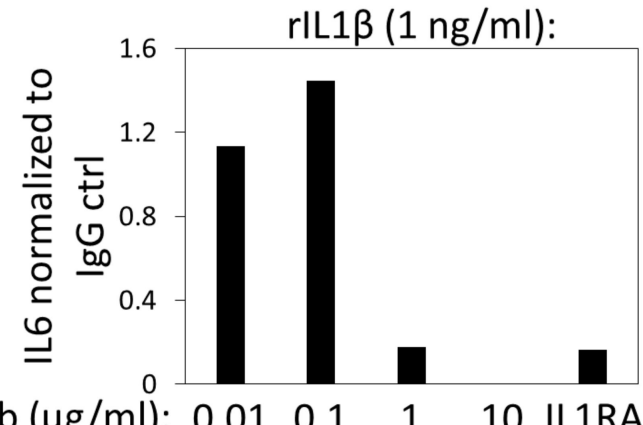

Anti IL1ß Ab $(\mu \mathrm{g} / \mathrm{ml}): \begin{array}{lllll}0.01 & 0.1 & 1 & 10 & \text { IL1RA }\end{array}$

3

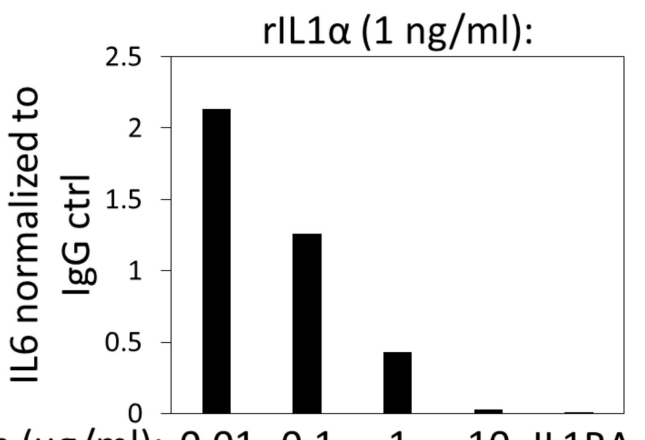

2

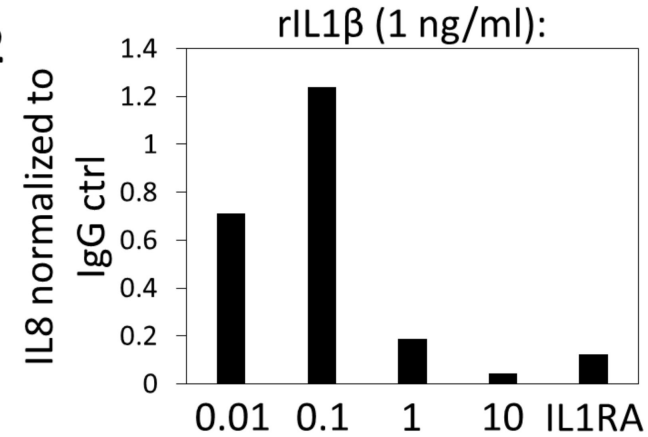

4

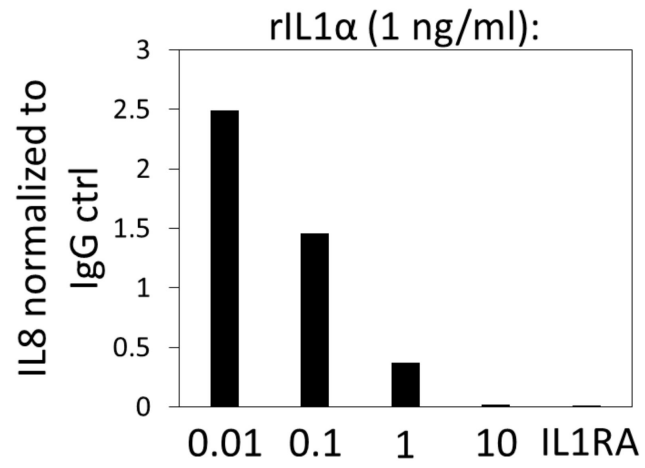

Anti IL1 $\alpha$ Ab $(\mu \mathrm{g} / \mathrm{ml}): 0.01 \quad 0.1 \quad 1 \quad 10$ IL1RA

Figure A2. IL1 $\beta$ and IL $1 \alpha$ neutralizing antibody validation and dose response. HBF were treated for $24 \mathrm{~h}$ with recombinant $(\mathrm{r}) \operatorname{IL} 1 \beta(1 \mathrm{ng} / \mathrm{mL} ; \mathbf{1}, 2)$ or $\operatorname{rIL} 1 \alpha(1 \mathrm{ng} / \mathrm{mL} ; 3,4)$ that had been pre-incubated with IgG, IL1 $\beta$ (clone $4 \mathrm{H} 5)$ or IL1 $\alpha$ (clone 7D4) neutralizing antibodies (doses indicated in figure) for $30 \mathrm{~min}$. After stimulation, HBF supernatants were assessed for IL6 and IL8 via ELISA $(n=1)$. 


\section{Appendix C}
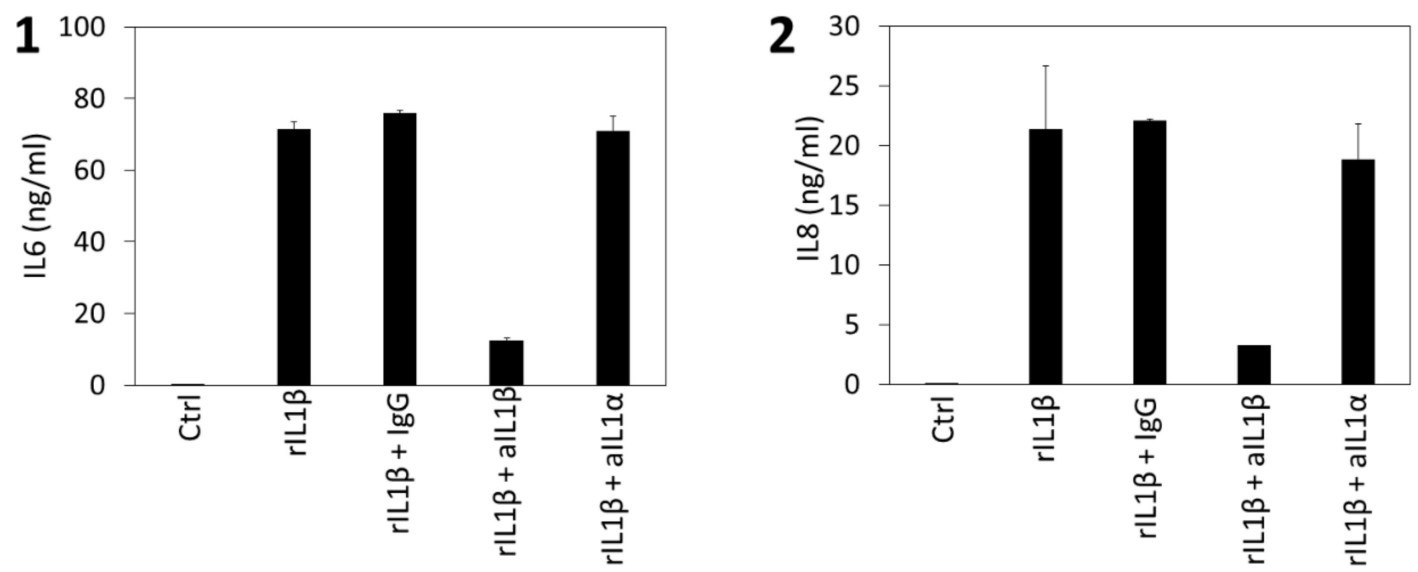

Figure A3. Cross validation of IL1 $\beta$ with IL1 $\alpha$ neutralizing antibody. HBF were treated with vehicle control (Ctrl) or recombinant (r)IL1 $\beta(1 \mathrm{ng} / \mathrm{mL})$, pre-incubated with IgG $(1 \mu \mathrm{g} / \mathrm{mL}), \operatorname{IL} 1 \beta$ (clone $4 \mathrm{H} 5,1 \mu \mathrm{g} / \mathrm{mL}$ ) or IL1 $\alpha$ (clone 7D4, 1 $\mu \mathrm{g} / \mathrm{mL}$ ) neutralizing antibodies for $30 \mathrm{~min}$. After stimulation, HBF supernatants were assessed for IL6 (1) and IL8 (2) via ELISA ( $n=2$ technical replicates).

\section{Appendix D}

Table A1. SBP-Ag subjects' characteristics.

\begin{tabular}{cc}
\hline Number & $\mathbf{1 8}$ \\
\hline Sex & 9 F, 9 M \\
\hline Age $(y r s)$ & $22 \pm 1^{*}$ \\
\hline Baseline FEV 1 (\% Predicted) & $96.9 \pm 2.1^{*}$ \\
\hline Antigens Used for Challenge & 8 Ragweed, 8 Dust mite, 2 Cat dander \\
\hline${ }^{*}$ Mean \pm SD.
\end{tabular}

\section{Appendix E}

Table A2. Cell \% change $48 \mathrm{~h}$ after SBP-Ag.

\begin{tabular}{ccc}
\hline Cell Type & Before Challenge & After Challenge \\
\hline Eosinophil & $2.2 \pm 3.9^{*}$ & $53.6 \pm 15.8^{*}$ \\
\hline Macrophage/monocyte & $87.8 \pm 8.1^{*}$ & $34.1 \pm 12.9 *$ \\
\hline Neutrophil & $1.5 \pm 1.4^{*}$ & $4.3 \pm 3.7^{*}$ \\
\hline Lymphocytes & $8.4 \pm 6.4^{*}$ & $7.9 \pm 4.1^{*}$ \\
\hline${ }^{*}$ Mean \pm SD. & &
\end{tabular}

\section{References}

1. Bousquet, J.; Chanez, P.; Lacoste, J.Y.; Barneon, G.; Ghavanian, N.; Enander, I.; Venge, P.; Ahlstedt, S.; Simony-Lafontaine, J.; Godard, P.; et al. Eosinophilic inflammation in asthma. N. Engl. J. Med. 1990, 323, 1033-1039. [CrossRef] [PubMed]

2. Malinovschi, A.; Fonseca, J.A.; Jacinto, T.; Alving, K.; Janson, C. Exhaled nitric oxide levels and blood eosinophil counts independently associate with wheeze and asthma events in National Health and Nutrition Examination Survey subjects. J. Allergy Clin. Immunol. 2013, 132, 821-827. [CrossRef]

3. Spencer, L.A.; Bonjour, K.; Melo, R.C.; Weller, P.F. Eosinophil secretion of granule-derived cytokines. Front. Immunol. 2014, 5, 496. [CrossRef]

4. Acharya, K.R.; Ackerman, S.J. Eosinophil granule proteins: Form and function. J. Biol. Chem. 2014, 289, 17406-17415. [CrossRef]

5. Esnault, S.; Leet, J.P.; Johansson, M.W.; Barretto, K.T.; Fichtinger, P.S.; Fogerty, F.J.; Bernau, K.; Mathur, S.K.; Mosher, D.F.; Sandbo, N.; et al. Eosinophil cytolysis on Immunoglobulin $\mathrm{G}$ is associated with microtubule formation and suppression of rho-associated protein kinase signalling. Clin. Exp. Allergy 2020, 50, 198-212. [CrossRef] 
6. Bernau, K.; Leet, J.P.; Esnault, S.; Noll, A.L.; Evans, M.D.; Jarjour, N.N.; Sandbo, N. Eosinophil-degranulation products drive a proinflammatory fibroblast phenotype. J. Allergy Clin. Immunol. 2018, 142, 1360-1363. [CrossRef] [PubMed]

7. Esnault, S.; Bernau, K.; Torr, E.E.; Bochkov, Y.A.; Jarjour, N.N.; Sandbo, N. RNA-sequencing analysis of lung primary fibroblast response to eosinophil-degranulation products predicts downstream effects on inflammation, tissue remodeling and lipid metabolism. Respir. Res. 2017, 18, 188. [CrossRef] [PubMed]

8. Al-Muhsen, S.; Johnson, J.R.; Hamid, Q. Remodeling in asthma. J. Allergy Clin. Immunol. 2011, 128, 451-462. [CrossRef]

9. Humbles, A.A.; Lloyd, C.M.; McMillan, S.J.; Friend, D.S.; Xanthou, G.; McKenna, E.E.; Ghiran, S.; Gerard, N.P.; Yu, C.; Orkin, S.H.; et al. A critical role for eosinophils in allergic airways remodeling. Science 2004, 305, 1776-1779. [CrossRef]

10. Mostaco-Guidolin, L.B.; Osei, E.T.; Ullah, J.; Hajimohammadi, S.; Fouadi, M.; Li, X.; Li, V.; Shaheen, F.; Yang, C.X.; Chu, F.; et al. Defective fibrillar collagen organization by fibroblasts contributes to airway remodeling in asthma. Am. J. Respir. Crit. Care Med. 2019, 200, 431-443. [CrossRef]

11. Fang, C.L.; Yin, L.J.; Sharma, S.; Kierstein, S.; Wu, H.F.; Eid, G.; Haczku, A.; Corrigan, C.J.; Ying, S. Resistin-like molecule-beta (RELM-beta) targets airways fibroblasts to effect remodelling in asthma: From mouse to man. Clin. Exp. Allergy 2015, 45, 940-952. [CrossRef]

12. Trivedi, S.G.; Lloyd, C.M. Eosinophils in the pathogenesis of allergic airways disease. Cell. Mol. Life Sci. 2007, 64, 1269-1289. [CrossRef]

13. Ayars, G.H.; Altman, L.C.; Gleich, G.J.; Loegering, D.A.; Baker, C.B. Eosinophil- and eosinophil granule-mediated pneumocyte injury. J. Allergy Clin. Immunol. 1985, 76, 595-604. [CrossRef]

14. Ohno, I.; Nitta, Y.; Yamauchi, K.; Hoshi, H.; Honma, M.; Woolley, K.; O’Byrne, P.; Tamura, G.; Jordana, M.; Shirato, K.; et al. Transforming growth factor beta 1 (TGF beta 1) gene expression by eosinophils in asthmatic airway inflammation. Am. J. Respir. Cell Mol. Biol. 1996, 15, 404-409. [CrossRef] [PubMed]

15. Gomes, I.; Mathur, S.K.; Espenshade, B.M.; Mori, Y.; Varga, J.; Ackerman, S.J. Eosinophil-fibroblast interactions induce fibroblast IL-6 secretion and extracellular matrix gene expression: Implications in fibrogenesis. J. Allergy Clin. Immunol. 2005, 116, 796-804. [CrossRef] [PubMed]

16. Dolgachev, V.; Berlin, A.A.; Lukacs, N.W. Eosinophil activation of fibroblasts from chronic allergen-induced disease utilizes stem cell factor for phenotypic changes. Am. J. Pathol. 2008, 172, 68-76. [CrossRef]

17. Esnault, S.; Johansson, M.W.; Kelly, E.A.; Koenderman, L.; Mosher, D.F.; Jarjour, N.N. IL-3 up-regulates and activates human eosinophil CD32 and alphaMbeta2 integrin causing degranulation. Clin. Exp. Allergy 2017, 47, 488-498. [CrossRef]

18. Terada, M.; Kelly, E.A.; Jarjour, N.N. Increased thrombin activity after allergen challenge: A potential link to airway remodeling? Am. J. Respir. Crit. Care Med. 2004, 169, 373-377. [CrossRef]

19. Kelly, E.A.; Esnault, S.; Liu, L.Y.; Evans, M.D.; Johansson, M.W.; Mathur, S.; Mosher, D.F.; Denlinger, L.C.; Jarjour, N.N. Mepolizumab attenuates airway eosinophil numbers, but not their functional phenotype, in asthma. Am. J. Respir. Crit. Care Med. 2017, 196, 1385-1395. [CrossRef] [PubMed]

20. Esnault, S.; Kelly, E.A.; Sorkness, R.L.; Evans, M.D.; Busse, W.W.; Jarjour, N.N. Airway factor XIII associates with type 2 inflammation and airway obstruction in asthmatic patients. J. Allergy Clin. Immunol. 2016, 137, 767-773. [CrossRef] [PubMed]

21. Esnault, S.; Khosravi, M.; Kelly, E.A.; Liu, L.Y.; Bochkov, Y.A.; Tattersall, M.C.; Jarjour, N.N. Increased IL-6 and Potential IL-6 trans-signalling in the airways after an allergen challenge. Clin. Exp. Allergy 2021. [CrossRef]

22. Sandbo, N.; Ngam, C.; Torr, E.; Kregel, S.; Kach, J.; Dulin, N. Control of myofibroblast differentiation by microtubule dynamics through a regulated localization of Mdiaj. Biol. Chem. 2013, 288, 15466-15473. [CrossRef] [PubMed]

23. Bernau, K.; Ngam, C.; Torr, E.E.; Acton, B.; Kach, J.; Dulin, N.O.; Sandbo, N. Megakaryoblastic leukemia-1 is required for the development of bleomycin-induced pulmonary fibrosis. Respir. Res. 2015, 16, 1-11. [CrossRef] [PubMed]

24. Schneider, C.A.; Rasband, W.S.; Eliceiri, K.W. NIH Image to ImageJ: 25 years of image analysis. Nat. Methods 2012, 9, 671-675. [CrossRef]

25. Esnault, S.; Kelly, E.A.; Johnson, S.H.; DeLain, L.P.; Haedt, M.J.; Noll, A.L.; Sandbo, N.; Jarjour, N.N. Matrix metalloproteinase-9dependent release of IL-1beta by human eosinophils. Mediat. Inflamm. 2019, 2019, 7479107. [CrossRef]

26. Esnault, S.; Kelly, E.A.; Nettenstrom, L.M.; Cook, E.B.; Seroogy, C.M.; Jarjour, N.N. Human eosinophils release IL-1ss and increase expression of IL-17A in activated CD4 + T lymphocytes. Clin. Exp. Allergy 2012, 42, 1756-1764. [CrossRef] [PubMed]

27. Esnault, S.; Kelly, E.A.; Schwantes, E.A.; Liu, L.Y.; DeLain, L.P.; Hauer, J.A.; Bochkov, Y.A.; Denlinger, L.C.; Malter, J.S.; Mathur, S.K.; et al. Identification of genes expressed by human airway eosinophils after an in vivo allergen challenge. PLoS ONE 2013, 8 , e67560. [CrossRef] [PubMed]

28. Tsakiri, N.; Kimber, I.; Rothwell, N.J.; Pinteaux, E. Interleukin-1-induced interleukin-6 synthesis is mediated by the neutral sphingomyelinase/Src kinase pathway in neurones. Br. J. Pharm. 2008, 153, 775-783. [CrossRef] [PubMed]

29. Lappalainen, U.; Whitsett, J.A.; Wert, S.E.; Tichelaar, J.W.; Bry, K. Interleukin-1beta causes pulmonary inflammation, emphysema, and airway remodeling in the adult murine lung. Am. J. Respir. Cell Mol. Biol. 2005, 32, 311-318. [CrossRef]

30. Garlanda, C.; Dinarello, C.A.; Mantovani, A. The interleukin-1 family: Back to the future. Immunity 2013, 39, 1003-1018. [CrossRef]

31. Weller, P.F.; Rand, T.H.; Barrett, T.; Elovic, A.; Wong, D.T.; Finberg, R.W. Accessory cell function of human eosinophils. HLA-DRdependent, MHC-restricted antigen-presentation and IL-1 alpha expression. J. Immunol. 1993, 150, $2554-2562$.

32. Chen, C.J.; Kono, H.; Golenbock, D.; Reed, G.; Akira, S.; Rock, K.L. Identification of a key pathway required for the sterile inflammatory response triggered by dying cells. Nat. Med. 2007, 13, 851-856. [CrossRef] 
33. Yousefi, S.; Gold, J.A.; Andina, N.; Lee, J.J.; Kelly, A.M.; Kozlowski, E.; Schmid, I.; Straumann, A.; Reichenbach, J.; Gleich, G.J.; et al. Catapult-like release of mitochondrial DNA by eosinophils contributes to antibacterial defense. Nat. Med. 2008, 14, 949-953. [CrossRef] [PubMed]

34. Ueki, S.; Konno, Y.; Takeda, M.; Moritoki, Y.; Hirokawa, M.; Matsuwaki, Y.; Honda, K.; Ohta, N.; Yamamoto, S.; Takagi, Y.; et al. Eosinophil extracellular trap cell death-derived DNA traps: Their presence in secretions and functional attributes. J. Allergy Clin. Immunol. 2016, 137, 258-267. [CrossRef]

35. Bernardo, M.E.; Fibbe, W.E. Mesenchymal stromal cells: Sensors and switchers of inflammation. Cell Stem Cell 2013, 13, $392-402$. [CrossRef] [PubMed]

36. Naylor, A.J.; Filer, A.; Buckley, C.D. The role of stromal cells in the persistence of chronic inflammation. Clin. Exp. Immunol. 2013, 171, 30-35. [CrossRef] [PubMed]

37. Eigenbrod, T.; Park, J.H.; Harder, J.; Iwakura, Y.; Nunez, G. Cutting edge: Critical role for mesothelial cells in necrosis-induced inflammation through the recognition of IL-1 alpha released from dying cells. J. Immunol. 2008, 181, 8194-8198. [CrossRef]

38. Denlinger, L.C.; Kelly, E.A.; Dodge, A.M.; McCartney, J.G.; Meyer, K.C.; Cornwell, R.D.; Jackson, M.J.; Evans, M.D.; Jarjour, N.N. Safety of and cellular response to segmental bronchoprovocation in allergic asthma. PLoS ONE 2013, 8, e51963. [CrossRef]

39. Kimura, H.; Inukai, Y.; Takii, T.; Furutani, Y.; Shibata, Y.; Hayashi, H.; Sakurada, S.; Okamoto, T.; Inoue, J.; Oomoto, Y.; et al. Molecular analysis of constitutive IL-1alpha gene expression in human melanoma cells: Autocrine stimulation through NF-kappaB activation by endogenous IL-1alpha. Cytokine 1998, 10, 872-879. [CrossRef]

40. Kawaguchi, Y.; McCarthy, S.A.; Watkins, S.C.; Wright, T.M. Autocrine activation by interleukin 1alpha induces the fibrogenic phenotype of systemic sclerosis fibroblasts. J. Rheumatol. 2004, 31, 1946-1954.

41. Weber, A.; Wasiliew, P.; Kracht, M. Interleukin-1 (IL-1) pathway. Sci. Signal. 2010, 3, cm1. [CrossRef] [PubMed] 